\title{
Business students' cheating in classroom and their propensity to cheat in the real world: a study of ethicality and practicality in China
}

\author{
Zhenzhong Ma
}

Received: 13 June 2011 / Accepted: 18 September 2011 /Published online: 12 October 2011

(C) Springer Science+Business Media B.V. 2011

\begin{abstract}
Widespread cheating among business students has been a great concern for educators and business managers in the West, but this issue is largely unexamined in Eastern cultures. This study explores the relationship between cheating at school and cheating in the real world in an international context by investigating Chinese business students' perception of ethicality and practicality of common business practice. The results show that many Chinese students have engaged in academic dishonesty at school. It was further found that Chinese students have a good understanding of what constitutes ethical behaviors in the real business world and the need for such behaviors. They also believe that business people fail to act in an ethical manner, yet they are unwilling to compromise their ethical standards in order to get ahead in their future career, except when they have a strong need for competitive success. The findings show that Chinese business students view the ethicality of an action as being more important than its practicality in the real business world even though they hold a completely opposite view in their classrooms. Concern arises when self-centered values like competitive success become more accepted in modern Chinese society.
\end{abstract}

Keywords Business ethics $\cdot$ China $\cdot$ Culture $\cdot$ Ethicality $\cdot$ Practicality

Widespread cheating among business students has been a great concern for both educators and business managers, and there is evidence that the problem may be increasing over time (Davis et al. 1992; Lawson 2004; Simkin and McLeod 2010). It was observed that students generally hold the belief that people in the business world act in an unethical manner, yet at the same time a large number of students admit having engaged in academic dishonesty, including cheating on exams and plagiarizing term papers. What causes the inconsistency between ethicality and practicality in business students remains relatively unknown (Lawson 2004). It is 
thus important to explore the relationship between business students' cheating in classroom and their propensity to cheat in the business world because it is only reasonable to assume that students who have successfully cheated at school will be more likely to fake a corporate report after they enter the business world (Simkin and McLeod 2010; White and Dooley 1993).

With the increasingly globalized world economy, it is equally important to explore whether such an inconsistency exists in other cultures. Scholars interested in cross-cultural differences in business ethics have started to apply business ethics theories, often developed in the West, to non-Western cultures in attempt to establish a commonly accepted ethical standards (Lam and Shi 2008; Lan et al. 2009; Ma 2010). The current study is to follow this line of research by examining business students' beliefs in China regarding the need for ethical behavior in a business setting and their actual behavior in an academic setting so as to provide a better understanding of cross-cultural differences in business ethics across the globe. Given that today's students are tomorrow's business leaders, their beliefs are very likely to affect the definition of acceptable business ethics, and their perceptions of what constitutes ethical behavior will influence the actions they take and business practices they advocate after they enter the business world.

Researchers have shown great interests in how culture might affect business ethics in China (e.g., Lam and Shi 2008; Lan et al. 2009; Rivers 2009), one of the most important emerging markets and probably the next economic superpower. However, the majority of the studies so far have dealt with people and business in Taiwan, Hong Kong, or Singapore, and only a few have dealt with business ethics in mainland China (Lam and Shi 2008; Ma 2010; von Weltzien Hoivik 2007). In order to bridge this knowledge gap in the studies of business ethics in China, the current study is intended to explore the cross-cultural differences in business students' perception of ethicality and practicality with a sample from mainland China. In addition, China is also a powerful test of the universalistic aspiration of Western theories on business ethics because Chinese culture is unique where there are a number of cultural barriers that make it very difficult or even impossible to impose Western standards and ethical codes. The investigation of perceptual similarities and differences in business ethics in China helps explore the unique characteristics of Chinese business ethics and facilitates the establishment of a commonly accepted ethical standard across the globe.

\section{Literature review and hypotheses}

College student cheating has become rampant (Simkin and McLeod 2010), and more is known about the pervasiveness of college student cheating than the relationship between their attitudes in the academic setting and the need for ethical behavior in the real world. A meta-study of 46 different studies on student cheating shows that on average $70 \%$ of the students have cheated in college (Whitley 1998), and newer studies indicate that up to $86 \%$ of college students have engaged in dishonest behaviors in their classes (Klien et al. 2007; McCabe et al. 2006), with considerable evidence showing that college cheating is still growing (Simkin and McLeod 2010). In addition, the fast development in technology has given students more access to 
different tools of cheating whereby students can buy term papers, course test banks, and solution manuals to textbooks over the Internet or use text messaging to send test answers during examinations or employ cell phones to take pictures and email test materials to other students (Etter et al. 2006). Of particular concern is the fact that business students continue to cheat more in different studies with student samples from a variety of majors (Simkin and McLeod 2010), and research seems to support the argument that business majors have lower ethics than other majors and business students have the highest cheating rate among business, engineering, science, and humanities students (Carauna and Ewing 2000; Harris 1989).

Recent experiences with financial disasters such as Enron and WorldCom and the economic recession caused by the subprime mortgage crisis have led the general public to ask "how could such things happen?" and motivated scholars to examine the link between student cheating and subsequent unethical behavior in the business world. A few studies have found a strong relationship between cheating at college and unethical behavior at work. For example, Nonis and Smith (2001) find that the tendency to cheat at work was highly correlated with the frequency of cheating in college, a finding echoed by Crown and Spiller (1998) and Lawson (2004) who find similar relationships between unethical workplace behavior and student cheating.

A variety of demographic variables have been related to business students' beliefs regarding unethical behavior in the business world and their behavior in the academic setting, including gender, grade level, academic performance, and personal value. Research on one of the most studied factors - gender-has produced mixed evidence regarding the effect of gender on the choice of ethical behavior: Many studies have concluded that females are more likely to choose ethical behavior, and female students are more concerned with ethical issues than their male counterparts (Lawson 2004; Sims et al. 1996), yet others find no conclusive evidence to support the existence of gender differences in ethical judgments (Crown and Spiller 1998).

Grade level and academic performance have also been widely studied in student cheating and their potential relationship with unethical behavior at the workplace. Similar to the research on gender differences, mixed evidence exists regarding the relationship between grade level and student's moral development (Lawson 2004). For instance, Davis and Welton (1991), based on their observation of an ethical maturation process from students' initial exposure to business courses through the graduate level, contend that students' perception of proper ethical behavior matures toward society's expectation throughout their college life, while Beltramini et al. (1984) find no significant difference in the ethical concerns of students across grade levels. With respect to academic performance, previous studies found that those students who do well academically are less likely to cheat than other students, and a review study of empirical research on students cheating also conclude that research continues to find a significant negative relationship between cheating and academic performance (Crown and Spiller 1998; Lawson 2004).

Personal value is another important factor that has received much attention from scholars in the field of business ethic research, yet surprisingly little has been devoted to exploring its potential impact on the relationship between student cheating and unethical behavior at the workplace (Nonis and Smith 2001; Simkin and McLeod 2010). Of particular relevance is the importance an individual accords to competitive success. The desire to win or the notion of "winning is everything" 
seems to lead students to simply use cheating as a tool to pursue their goals at school, but the relationship between the importance of competitive success and its impact on student's belief regarding what constitutes ethical behavior at the workplace remains understudied.

The current literature on student cheating has generated some evidence for the relationship between student cheating and unethical behavior at the workplace. Investigation of the relationship between cheating at school and cheating at the workplace is important because the propensity to cheat at school is likely to carry over to the workplace and it is very likely that a student who has successfully cheated on an exam or a term paper might be cheating again on company reports after entering the business world. Business schools are preparing future business leaders, and it is crucial for them to help business students understand and internalize ethical behaviors at the college level in the hope that students will carry over ethical behaviors to their future employment.

While the studies examining student cheating and unethical behavior at the workplace were mainly conducted in the West (Lawson 2004; Simkin and McLeod 2010), the current study will move forward this line of research by investigating this issue in a Chinese context and explore the relationship of ethicality and practicality perceived by business students in China, which will be able to enrich the literature of cross-cultural research on business ethics. This study will enrich the literature by examining business students' beliefs regarding the need for ethical behavior in the real world and their action in an academic setting in China. This study will also examine the impact of gender, grade level, academic performance, and importance of competitive success on Chinese business students' perception of ethicality and practicality as well as the link between their attitude toward classroom cheating and unethical behavior at the workplace. The key question to answer is whether business student cheating is related to their propensity to cheat in the real business world in China, with the following hypotheses developed based on the literature to be tested in this study:

H1a: Business students in China generally believe people in the real business world act in an unethical manner.

H1b: Business students in China tend to believe unethical behavior is necessary to get ahead in the business world.

H2a: Female business students in China are more likely to agree with the need for ethical behavior in the business world.

$\mathrm{H} 2 \mathrm{~b}$ : Business students in the higher grade level in China are more likely to agree with the need for ethical behavior in the business world.

H2c: Business students with better academic performance in China are more likely to agree with the need for ethical behavior in the business world.

H3a: Business students who have engaged in academic dishonesty will hold lower ethical beliefs with respect to behavior in the business world.

H3b: The more upset with academic dishonesty in their class, the more likely that Chinese business students will hold higher ethical beliefs with respect to behavior in the business world.

H3c: The more importance Chinese business students accord to competitive success, the more likely they will hold lower ethical beliefs with respect to behavior in the business world. 


\section{Method}

The participants of this study were 205 business students attending a major university in a coastal city of China, at both the graduate and undergraduate levels. They participated in this study on a voluntary basis during their regular class time, and no remuneration was offered. The participants had an average age of $23.9(\mathrm{SD}=3.5)$, with $77.1 \%$ of them from graduate schools. The average years of experience was 3.45 $(\mathrm{SD}=1.57)$, and $44.3 \%$ of the participants were male. A breakdown of the participants by gender, grade level, and academic performance is reported in Table 1.

The main method for data collection was a self-administered questionnaire with confidentiality ensured. The confidentiality issue was particularly important in this study because participants were asked for information regarding whether they have engaged in any dishonest behavior in an academic setting. To make sure students answer the questions in an honest manner, strict anonymity was ensured and absolutely no student ID or student name or any piece of information that may be used for identification was collected in the study. The participants were asked in the questionnaire for their demographic information, including gender, age, work experience, grade level, academic performance, and personal value in terms of the importance of competitive success in their lives. The importance an individual accords to competitive success was developed from a five-point Likert scale used in other cross-cultural studies (Ma 2010; Wagner 1995), which consists of five items, with sample questions including "Success is the most important thing in life" (reliability alpha was 0.81 ).

In addition to demographic questions, participants were asked to express their degree of agreement with seven statements that primarily dealt with ethical behavior in the real world. These statements have been used in other similar studies with proven validity in such studies (Lawson 2004). One of the statements from previous

Table 1 Demographic characteristics of the sample $(N=205)$

\begin{tabular}{lcr}
\hline & Mean & Percentage \\
\hline Gender & 1.56 & \\
1=Male & & 44.3 \\
2=Female & & 55.7 \\
Grade level & 4.74 & \\
1=U/G freshman & & 2.1 \\
2=U/G sophomore & 2.1 \\
3=U/G junior & 12.2 \\
4=U/G senior & & 6.4 \\
5=MBA year 1 & 56.9 \\
6=MBA year 2 & & 20.2 \\
GPA & \\
1=Average & \\
2=Good & & 7.4 \\
3=Very good & & 29.8 \\
4=Excellent & & 46.3 \\
\hline
\end{tabular}


studies was revised to fit with the situation in China: Using a fake ID to buy alcohol was replaced with using a fake ID to enter Internet Café because there is no restriction on who can buy alcohol in China but Internet Café owners are not allowed to let in young people under certain age or without an ID. Participants were asked to indicate their agreement with these seven statements on a five-point Likert scale, with 1 indicating that the student strongly disagreed with the statement and 5 strongly agreed with the statement.

Student participants were also asked to express their opinion with regard to two types of dishonest behaviors at school: cheating on an exam and plagiarizing a term paper or assignment. For each type of dishonest behaviors, students were asked (1) whether they had engaged in such a behavior and (2) whether they would be upset by other students' engaging in such a behavior. Responses to the first set of questions can be chosen from "yes," "no, but would if given the opportunity," and "no, and would not because it is wrong." Responses to the second set questions were measured using a five-point Likert scale with 1 indicating that the student was not upset at all with that type of behavior and 5 strongly upset with the discussed dishonest behavior.

To test the hypotheses, one-sample $T$ test and a nonparametric statistic (Kendall tau-B) were used in this study. Use of a nonparametric statistic was desirable in this study because of the non-normality of the distribution of various responses. The Kendall tau-B statistic measures the association between two measured quantities/ variables, and it reflects the similarity of the ordering of the data when ranked by each set of variables/variables.

\section{Results}

Table 1 reports the breakdown of the participants by gender, grade level, and academic performance, and Table 2 reports the responses to the seven statements regarding ethical behavior in a nonacademic setting. Results of one-sample $T$ test performed using the population mean and the neutral position ("neither disagree nor agree") were reported in the last two columns of Table 2 to test whether Chinese business students' general belief is significantly different from the neutral position.

\section{Attitude toward ethical behavior in the real world}

It is consistent with the prediction business students in China generally believe that people in the business world fail to act in an ethical manner (refer to Table 2, line 4). As many as $44 \%$ of the students believe people in the business world fail to act in an ethical manner, while only $28 \%$ of the students think it is the opposite. Hypothesis $1 \mathrm{a}$ is thus supported (at the level of $p<0.007$ ), similar to the findings in the West.

The test of the responses also shows that Chinese business student's beliefs regarding what is ethical behavior in the business world is consistent with what is generally considered ethical. They agree with the idea that "good ethics is good business" and disagree with the idea that "it is ok to lie to a potential employer on an employment application." Furthermore, they disagree with the idea that "it is ok to use a fake ID or someone else's ID to enter an Internet Café." 
Table 2 Attitudes toward unethical behavior in a nonacademic setting

\begin{tabular}{lcccc}
\hline & Mean & Standard deviation & $T$ statistics & Sig. (two-tailed) \\
\hline $\begin{array}{l}\text { It is ok to lie to a potential employer } \\
\text { on an employment application. }\end{array}$ & 2.71 & 1.16 & $-3.45^{* * *}$ & 0.001 \\
$\begin{array}{l}\text { It is ok to use a fake ID or someone else's } \\
\quad\end{array}$ & 2.81 & 1.24 & $-2.20^{*}$ & 0.029 \\
$\quad \begin{array}{l}\text { ID to enter an Internet Café. } \\
\begin{array}{l}\text { The use of insider information when buying } \\
\text { and selling stock is unethical behavior. }\end{array}\end{array}$ & 3.13 & 1.17 & 1.53 & 0.128 \\
$\begin{array}{l}\text { In general, people in the business world act } \\
\text { in an ethical manner. }\end{array}$ & 2.76 & 1.22 & $-2.71^{* *}$ & 0.007 \\
$\begin{array}{l}\text { In order to get ahead in your future career } \\
\quad \text { you will have to compromise your }\end{array}$ & 2.52 & 1.23 & $-5.42^{* * *}$ & 0.000 \\
$\quad$ ethical standards. & & & & \\
$\begin{array}{l}\text { Good ethics is good business. } \\
\text { Ethics: either you have them or you don't. }\end{array}$ & 2.75 & 1.16 & $-2.96^{* *}$ & 0.003 \\
\hline
\end{tabular}

Given that Chinese business students believe that people in the real business world generally act in an unethical manner and they understand the differences between what is ethical and what is unethical, it is therefore important to ask the question whether these students will maintain their ethical standards when they enter the real business world. The participants of this study were clearly standing on the ethical side: The responses to the statement "in order to get ahead in your future career you will have to compromise your ethical standards" were significantly different from the neutral position ("neither agree nor disagree"). More than twice as many students disagreed with this statement as those who agreed with this statement $(52.8 \%$ vs. $23.1 \%)$, including $25.1 \%$ of the students who strongly disagreed and $27.7 \%$ of the students who disagreed and $15.9 \%$ of the students who agreed and only $7.2 \%$ of the students who strongly agreed. Hypothesis $1 \mathrm{~b}$ is thus rejected, different from what was found in the West. In other words, while Chinese business students believe people in the real business world act in an unethical manner, they do not think it is necessary to compromise their ethical standards in order to get ahead in their future career.

In addition, the responses to the last question also show that Chinese business students tend to believe there is a gray area in what constitute ethical behaviors in the business world and there are no clear-cut choices. The results show that over $43 \%$ of the students disagreed with the statement "ethics: either you have them or you don't," and only $23.5 \%$ of the students believed so, with the rest holding a neutral position ("neither disagree nor agree").

\section{Impact of demographic variables}

With respect to the impact of demographic variables, gender was a significant variable regarding perceptions of ethical behavior in the business world, but only to a certain extent. The first column of Table 3 presents the degree of association 
Table 3 Effect of gender, GPA, and grade level on attitude toward ethical behavior in a nonacademic setting

\begin{tabular}{|c|c|c|c|}
\hline & \multicolumn{3}{|c|}{ Kendall's tau-B statistic } \\
\hline & Gender & GPA & Grade level \\
\hline It is ok to lie to a potential employer on an employment application. & -0.06 & 0.14 & 0.12 \\
\hline It is ok to use a fake ID or someone else's ID to enter an Internet Café. & -0.09 & 0.09 & -0.04 \\
\hline $\begin{array}{l}\text { The use of insider information when buying and selling stock is } \\
\text { unethical behavior. }\end{array}$ & -0.10 & 0.11 & -0.04 \\
\hline In general, people in the business world act in an ethical manner. & -0.02 & -0.00 & $-0.18 *$ \\
\hline $\begin{array}{l}\text { In order to get ahead in your future career you will have to } \\
\text { compromise your ethical standards. }\end{array}$ & $-0.24 * *$ & -0.10 & -0.05 \\
\hline Good ethics is good business. & $0.25 * *$ & -0.05 & 0.01 \\
\hline Ethics: either you have them or you don't. & -0.05 & -0.00 & -0.05 \\
\hline
\end{tabular}

In the first column, a positive (negative) sign for the Kendall's tau-B statistic indicates that women (men) agreed more than men (women) with the given statement; in the second column, a positive (negative) sign indicates a student with a high (low) GPA agreed more with the given statement than a student with a low (high) GPA; in the last column, a positive (negative) sign indicates that a student in higher (lower) grade level agreed more with the given statement than a student in lower (higher) grade level

$* p<0.01 ; * * p<0.001$ (two-tailed)

between gender and various statements regarding ethical behavior in the business world as measured by the Kendall's tau-B statistic. A positive sign for the tau-B statistic indicates that female students agreed more than male students with a given statement, and a negative sign indicates that male students agreed more than female students with a given statement. Among seven statements, only two show gender differences in the belief what makes ethical behavior: Female students agreed more with the idea "good ethics is good business" $(p<0.001)$, while male students agreed more with the idea "in order to get ahead in your future career you will have to compromise your ethical standards" $(p<0.001)$. No significant gender difference was found in other statements, and thus, hypothesis $2 \mathrm{a}$ is partially supported.

It has been found that the most successful students are more likely to hold more ethical beliefs in the West, yet the current study did not find any significant relationship between academic performance as measured by grade point average and the statements regarding ethical behavior in a nonacademic setting. Hypothesis 2c is rejected. Furthermore, when the impact of grade level was considered, only one statement was found significantly related to the grade level, which is "in general, people in the business world act in an ethical manner." The negative sign indicates that the higher the grade level, the less likely the students would believe people in the business world act in an ethical manner. Hypothesis $2 \mathrm{~b}$ is thus rejected. Such a result is opposite to the findings of Davis and Welton's (1991) study which supports an ethical maturation process along with student's progress through the college. Instead, this study adds more evidence for the existence of a mixed relationship between grade level and student's moral development (Lawson 2004). 
Relationship between cheating at school and ethical behavior in the business world

The results of this study indicated that there is a moderately strong relationship between business students' propensity to engage in unethical behavior in an academic setting and their attitude toward such behaviors in the business world in China, similar to what was found in the West (please refer to Tables 4 and 5). Table 4 reports the results regarding business students' cheating in an academic setting in China. It shows that about $43.9 \%$ of the students have personally cheated in an exam and $75.8 \%$ have plagiarized a term paper or assignment, adding up to $77.8 \%$ of the students surveyed having the experience of either cheating on an exam or plagiarizing a term paper or assignment, a situation close to that in the West. The one-sample $T$ test for the academic dishonesty (with test value=2, representing "no, but would if given the opportunity") shows that Chinese business students' attitudes regarding their own academic dishonesty are significantly different from "no, but would if given the opportunity" and "no, and would not because it is wrong," which is consistent with the result that the majority of them admitted that they had committed academic dishonesty at school. The bottom part of Table 4 indicates that students would not feel upset by others' cheating either on an exam or a term paper or assignment. In particular, the surveyed students would be very unlikely to feel upset by cheating on plagiarizing (at a level of $p<0.001$, based on one-sample $T$ test with test value $=3$, a neutral position).

Table 5 reports the degree of association between students' responses to the two measures of students' beliefs regarding ethics in an academic setting (that is, the propensity to engage in academic dishonesty including cheating on exams and plagiarizing a term paper or assignment and the extent to which they are upset by others' cheating in their classes) and their responses to the seven situations regarding ethics in the business world. The strength of the association is again measured by Kendall's tau-B statistic, and the related levels of significance are reported. The results indicate that business students who cheated on exams or plagiarized papers or assignments were more likely to accept the need for unethical behavior in the real world than those who did not engage in academic dishonesty. More specifically, students who cheated on exams or papers were more likely to believe it is acceptable to lie to a potential employer on an employment application and it is ok to use a fake ID or someone else's ID to enter an Internet Café. In addition, they were less likely

Table 4 Students' attitude toward unethical behavior in an academic setting

\begin{tabular}{llcr}
\hline & Mean & Standard deviation & $T$ statistics \\
\hline Have personally & & & $-2.44^{*}$ \\
Cheated on an exam $(43.9 \%)$ & 1.85 & 0.85 & $-12.01^{* *}$ \\
Plagiarized a term paper/assignment $(75.8 \%)$ & 1.38 & 0.72 & -1.89 \\
Would be upset by & & 1.32 & $-9.03 * *$ \\
Another person's cheating on an exam & 2.82 & 1.17 & 2.25 \\
Another person's plagiarizing a term paper/assignment & 2.17 & & \\
\hline
\end{tabular}

${ }^{*} p<0.05 ; * * p<0.001$ (two-tailed) 
Table 5 Relationship between academic dishonesty and attitude towards unethical behavior in a nonacademic setting

\begin{tabular}{|c|c|c|c|c|c|}
\hline & \multicolumn{5}{|c|}{ Kendall's tau-B statistic } \\
\hline & \multicolumn{2}{|c|}{$\begin{array}{l}\text { Propensity to engage } \\
\text { in academic dishonesty }\end{array}$} & \multicolumn{2}{|c|}{$\begin{array}{l}\text { Upset by academic } \\
\text { dishonesty }\end{array}$} & \multirow{2}{*}{$\begin{array}{l}\text { Perceived } \\
\text { importance o } \\
\text { Competitive } \\
\text { success }\end{array}$} \\
\hline & $\begin{array}{l}\text { Cheating on } \\
\text { an exam }\end{array}$ & $\begin{array}{l}\text { Plagiarizing } \\
\text { a term paper }\end{array}$ & $\begin{array}{l}\text { Cheating on } \\
\text { an exam }\end{array}$ & $\begin{array}{l}\text { Plagiarizing } \\
\text { a term paper }\end{array}$ & \\
\hline $\begin{array}{l}\text { It is ok to lie to a potential } \\
\text { employer on an employment } \\
\text { application. }\end{array}$ & $-0.17^{* *}$ & -0.04 & -0.08 & $-0.13^{*}$ & 0.05 \\
\hline $\begin{array}{l}\text { It is ok to use a fake ID or } \\
\text { someone else's ID to enter } \\
\text { an Internet Café. }\end{array}$ & $-0.18^{* *}$ & -0.10 & -0.02 & -0.04 & $0.20 * * *$ \\
\hline $\begin{array}{l}\text { The use of insider information } \\
\text { when buying and selling stock } \\
\text { is unethical behavior. }\end{array}$ & 0.07 & $0.13 *$ & 0.04 & -0.01 & $0.13 *$ \\
\hline $\begin{array}{l}\text { In general, people in the business } \\
\text { world act in an ethical manner. }\end{array}$ & $0.14 *$ & 0.06 & 0.08 & 0.11 & 0.05 \\
\hline $\begin{array}{l}\text { In order to get ahead in your } \\
\text { future career you will have } \\
\text { to compromise your ethical } \\
\text { standards. }\end{array}$ & -0.06 & 0.04 & 0.02 & 0.10 & $0.26^{* * *}$ \\
\hline Good ethics is good business. & 0.12 & 0.02 & 0.12 & -0.00 & -0.04 \\
\hline $\begin{array}{l}\text { Ethics: either you have them or } \\
\text { you don't. }\end{array}$ & -0.05 & -0.01 & 0.03 & 0.11 & 0.09 \\
\hline
\end{tabular}

In the first two columns, a negative (positive) sign for the Kendall's tau-B statistic indicates that students who engaged in academic dishonesty agreed more (less) than those who did not with the given statement; in the second two columns, a positive (negative) sign indicates that students feeling upset with academic dishonesty agreed (less) more than those who did not feel upset with the given statement; in the last column, a positive (negative) sign indicates that students who perceived high importance of competitive success agreed more (less) with the given statement

${ }^{*} p<0.05 ; * * p<0.01 ; * * * p<0.001$ (two-tailed)

to believe that people in the business world generally act in an ethical manner or good ethics is good business (at a marginal level). Given that Chinese business students did not feel upset with their peers' cheating either on exams or term papers or assignments, no relationship was found between the extent to which students felt upset with the academic dishonesty and the extent to which they believed that unethical behavior was acceptable in the business world, except that students who felt very upset with plagiarizing papers or assignments would be less likely to believe it is ok to lie to a potential employer on an employment application. The results partially supported hypothesis $3 \mathrm{a}$ and, to a lesser extent, supported hypothesis $3 \mathrm{~b}$. In other words, Chinese business students who have engaged in academic dishonesty will hold lower ethical beliefs with respect to behavior in the real business world and students who feel very upset with academic dishonest behavior will hold higher ethical beliefs with respect to behavior in the real business world, and thus, a moderately strong relationship was found between Chinese business students' cheating at school and their beliefs regarding ethical behavior in the business world. 
A moderately strong relationship was also observed between the importance of competitive success and student's attitude toward unethical behavior in the business world. As shown in the last column of Table 5, students who accorded more importance to competitive success were more likely to believe it is ok to use a fake ID or someone else's ID to enter Internet Café and were more likely to agree that in order to get ahead in your future career you will have to compromise your ethical standards, but, to a lesser extent, they still believed the use of insider information when buying and selling stock is unethical behavior, which thus provides partial support for hypothesis $3 \mathrm{c}$.

\section{Discussion}

This study began with the notion that business student cheating has become a great concern in the West both for educators and for business practitioners. The rampant student cheating has motivated scholars to examine the relationship between student cheating at school and various business scandals and unethical behaviors, with evidence from the West supporting a strong relationship between cheating in classroom and cheating at the workplace. This study then attempted to explore whether this carryover effect also exists in the East to enrich the literature on cross-cultural research on business ethics. The results from this study supported a moderately strong relationship between business student cheating and their propensity to cheat in the business world in China, with some unique findings that contribute to the current business ethics literature mainly based on the studies conducted in the West.

This study shows that the widespread student cheating also exists in China. Close to $80 \%$ of the surveyed business students admitted that they had engaged in dishonest behavior including cheating on exams and plagiarizing term papers or assignments, at a similar level to those found in the West. Considering the responses were based on a self-reported questionnaire, there is a reason to believe the actual situation could be worse. The pervasiveness of student cheating across the global deserves more attention from all interested parties and stakeholders.

In addition, the Chinese business students surveyed also believe that people in the real business world has failed to act in an ethical manner, similar to the findings of the studies conducted in the West. The belief that unethical behaviors prevail in the business world may in fact lead to such behaviors, which is in particular true when combined with the fact that Chinese business students do not feel upset by their peers' unethical behaviors such as cheating on exams or plagiarizing term papers. The high level of tolerance of unethical behavior in the academic setting may lead to more student cheating, and the belief of widespread unethical behavior in the business world will increase the possibility that academic dishonesty will be carried over to the workplace, which could be more problematic for interested stakeholders and policymakers who are trying to reduce unethical behavior in the business world at all costs. Of course, the causes behind cheating in the real business world are more complicated than cheating in the classroom. Future empirical research, in particular longitudinal research, is called on to explore the correlations between cheating in the classroom and actual cheating in the real business world. 
It is interesting to notice the inconsistency between Chinese business students' belief regarding unethical behavior in the business world and their own lack of ethics, again similar to the one found in the West on business students. In other words, while Chinese business students disapprove of unethical behaviors in the business world, they still commit dishonest behaviors in an academic setting, which creates a dilemma between ethicality and practicality. Research shows that business students prefer to act ethically when other variables are held constant and business students also prefer to act practically when other variables are held constant (White and Dooley 1993, p. 649), but unfortunately ethicality and practicality are often at odds with each other. It may not be practical to act consistently with one's own ethical judgment. What these students would do when ethicality and practicality are really at odds becomes very important. The results from this study show that Chinese business students choose to stand on their moral standards when forced to choose between ethicality and practicality. Regarding the statement "in order to get ahead in your future career you will have to compromise your ethical standards," more than twice as many students disagree with this statement as those who agree with this statement (52.8\% vs. 23.1\%), a finding quite different from those of similar studies in the West where business students believe unethical behavior is necessary in order to get ahead in their career and students prefer a practical approach over an ethical approach if forced to choose between the two (Lawson 2004; White and Dooley 1993).

While it is comforting to see that Chinese business students choose ethicality over practicality and are not willing to compromise their ethical standards in order to advance their future career, their own behavior in an academic setting seems to point to another direction: They choose to cheat on exams or plagiarize term papers and tolerate their peers' dishonest behaviors. What causes this inconsistency remains unknown. One explanation is that the difference between students' behavior and their perceptions of others actions may be due to information asymmetry (Lawson 2004). When they make a decision with an ethical component, all the information relevant to that decision can be taken into consideration with appropriate weights, yet as observers of a decision-making process with an ethical component, they may not be aware of all the information regarding the context where the decision is made, which will affect its practicality, and thus believe it is unethical. But if given all the information relevant to the situation, they may very well have made the same practical decision. Future research should look into this direction to investigate the underlying causes for this inconsistency in their different choices between ethicality and practicality (Lawson 2004).

In addition, even though Chinese business students are generally unwilling to compromise their moral standards in order to get ahead in their future career, the strong relationship between their perception of the importance of competitive success and their propensity in the business world is still worrisome. Chinese students who accorded high importance to competitive success are more likely to agree that it is ok to use a fake ID or someone else's ID to enter an Internet Café and, more importantly, they are more likely to agree with the idea that "in order to get ahead in your future career you will have to compromise your ethical standards" (with a significance level at $p<0.0001$ ). In other words, while Chinese business students do not like to compromise their moral principles just to get ahead in their 
career, they would do so if they strongly believe in the competitive success, a phenomenon that has become widespread among modern Chinese people, in particular among young Chinese that have a high level of exposure to Western influences where competition and individual success is so highly valued. With China's economy increasingly integrated into Western economies, the strong influence from the West and individual interests and self-centered values have begun to challenge the collectivistic cultural values in China. If this situation continues and there is no reason to believe it will stop in the near future, it is expected more students would believe that it is necessary to compromise their moral standards in order to get ahead in their career, more similar to what was found in the West, but may not be a good signal for the Chinese. Future research should explore the impact of the influence from the West on business ethics in China.

Another interesting finding of this study is that close to half of the Chinese students surveyed believe there is a gray area regarding what is ethical and what is not, which is quite different from what was found in the West (Lawson 2004). Over $43 \%$ of the students disagreed with the statement "ethics: either you have them or you don't." This finding is consistent with the argument that what is ethics and what is not in China is somehow context dependent, a utilitarian perspective (Ma 2010). The Chinese often need to relate to a particular context in order to make a decision regarding ethics, rather than base on an absolute moral principle. Future research could examine what impact this might have on Chinese people with respect to ethicality and practicality.

Given that Chinese business students have a fairly good understanding of what constitutes ethical or unethical behavior, readers may wonder whether it is possible to foster ethical behaviors at school and hope they can further carry over ethical behaviors to their workplace in future. Research on why students cheat provides some important suggestions that may help reduce student cheating at school in China: The presence of a moral anchor in a faculty member whose opinion matters to students will have positive influence on students (Simkin and McLeod 2010). Compared with the influence of family or friends, the influence of professors on students, in particular for students who chooses not to cheat, is significant, and professors may sometime act as moral anchors or moral role models to positively influence students not to cheat (Simkin and McLeod 2010), which also proves that faculty members' efforts to restrain students from cheating are both desirable and valuable.

Another important finding from research on student cheating that may help reduce student cheating is to include business ethics courses and training at school, especially for business students. In training these future business managers, it is essential to expose them to the complexities of real-world business decision making with ethical components so as to sharpen students' ethical decision-making skills (Lawson 2004). In addition, since the perception of competitive success appear to significantly affect students' attitude toward dishonesty behaviors at school, case studies involving individuals who cheat to get ahead but who subsequently suffer significant negative consequences would be useful to help student realize the consequences of dishonest behaviors, and of course, building a moral culture at school that encourages students to do what is right rather than do what is personally best is of paramount importance. 
Acknowledgments This study was partially supported by a Standard Research Grant of the Social Sciences and Humanities Research Council of Canada (SSHRC \#410-2009-0271).

\section{References}

Beltramini, R., Peterson, R., \& Kormetsky, G. (1984). Concerns of college students regarding business ethics. Journal of Business Ethics, 3, 195-200.

Carauna, A., \& Ewing, M. T. (2000). The effect of anomie on academic dishonesty of university students. International Journal of Educational Management, 14(1), 23-29.

Crown, D. F., \& Spiller, M. S. (1998). Learning from the literature on collegiate cheating: A review of empirical research. Journal of Business Ethics, 17(6), 683-700.

Davis, J., \& Welton, R. (1991). Professional ethics: Business students' perceptions. Journal of Business Ethics, 10, 451-463.

Davis, S. F., Grover, C. A., Becker, A. H., \& McGregor, L. N. (1992). Academic dishonesty: Prevalence, determinants, techniques, and punishments. Teaching of Psychology, 19(1), 16-20.

Etter, S., Cramer, J., \& Finn, S. (2006). Origins of academic dishonesty: Ethical orientations and personality factor associated with attitudes about cheating with information technology. Journal of Research on Technology in Education, 39(2), 133-155.

Harris, J. (1989). Ethical values and decision process of male and female business students. The Journal of Education for Business, 64(5), 234-238.

Klien, H. A., Levenburg, N. M., McKendall, M., \& Mothersell, W. (2007). Cheating during the college years: How do business students compare? Journal of Business Ethics, 72, 197-206.

Lam, K., \& Shi, G. (2008). Factors affecting ethical attitudes in mainland China and Hong Kong. Journal of Business Ethics, 77, 463-479.

Lan, G., Ma, Z., Cao, J., \& Zhang, H. (2009). A comparison of personal values of Chinese accounting practitioners and students. Journal of Business Ethics, 88(Supplement 1), 59-76.

Lawson, R. A. (2004). Is classroom cheating related to business students' propensity to cheat in the "real world"? Journal of Business Ethics, 49, 189-199.

Ma, Z. (2010). The SINS in business negotiation: Explore the cross-cultural differences in business ethics between Canada and China. Journal of Business Ethics, 91(Supplement 1), 123-135.

McCabe, D. L., Butterfield, K. D., \& Trevino, L. K. (2006). Academic dishonesty in graduate business programs: Prevalence, causes, and proposed action. The Academy of Management Learning and Education, 5(3), 294-305.

Nonis, S., \& Smith, C. (2001). Personal value profiles and ethical business decision. Journal of Education for Business Ethics, 76(5), 251-256.

Rivers, C. (2009). Negotiating with the Chinese: EANTs and all. Thunderbird International Business Review, 51(5), 473-489.

Simkin, M. G., \& McLeod, A. (2010). Why do college students cheat? Journal of Business Ethics, 94(3), $441-453$.

Sims, R., Cheng, H., \& Teegen, H. (1996). Toward a profile of student software piraters. Journal of Business Ethics, 15, 839-849.

Von Weltzien Hoivik, H. (2007). East meets west: Tacit messages about business ethics in stories told by Chinese managers. Journal of Business Ethics, 74, 457-469.

Wagner, J. A. (1995). Studies of individualism-collectivism: Effects on cooperation in groups. Academy of Management Journal, 38(1), 152-172.

White, C., \& Dooley, R. (1993). Ethical or practical: An empirical study of students' choices in simulated business scenarios. Journal of Business Ethics, 12, 643-651.

Whitley, B. (1998). Factors associated with cheating among college students: A review. Research in Higher Education, 39, 235-274. 